ORIGINAL ARTICLE

\title{
Spectrum of Imipenem and Meropenem Susceptibilities amongst Gram Negative Rods
}

\author{
SADIA IKRAM ${ }^{1}$, ANILA ERRUM ${ }^{2}$, ASMA INAM ${ }^{3}$, FARRUKH SARFARAZ ${ }^{4}$, SADIA MAJEED ${ }^{5}$, SAIMA PERVAIZ ${ }^{6}$, SOHAILA \\ MUSHTAQ $^{7}$ \\ ${ }^{1}$ Associate Professor, ${ }^{7}$ Professor, Department of Pathology, Azra Naheed Medical College, Superior University, Lahore \\ ${ }^{2}$ Assistant Professor, Department of Pharmacology, Azra Naheed Dental College, Superior University, Lahore \\ ${ }^{3}$ Associate Professor, Department of Pharmacology, Azra Naheed Medical College, Superior University, Lahore \\ ${ }^{4}$ Assistant Professor, Department of Medical Education, Azra Naheed Medical College, Superior University, Lahore \\ ${ }^{5}$ Assistant Professor, Department of Pharmacology, Continental Medical College, Lahore \\ ${ }^{6}$ Assistant Professor, Department of Pathology, Azra Naheed Dental College, Superior University, Lahore \\ Correspondence to: Sadia Ikram, Cell: 0323-5315347, E-mail: dr_sadia.sajid@hotmail.com
}

\begin{abstract}
Aim: To compare the resistance amongst Gram negative bacteria against imipenem and meropenem.

Study Design: Prospective, non-randomized, descriptive study.

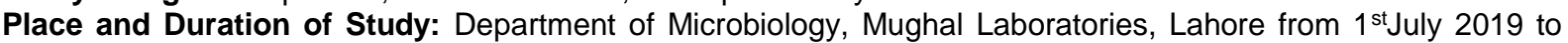
$31^{\text {st }}$ December 2019.

Methodology: One hundred culture samples received, bacteria isolated and their susceptibilities to imipenem and meropenem were compared. Organisms were recognized by the microbiological techniques according to the current standards and susceptibility testing was done according to the guidelines of Clinical and Laboratory Standards Institute (CLSI) 2020by using Kirby Bauer Disc diffusion method.

Results: Salmonella typhi, Citrobacter species and Proteus species were $100 \%$ sensitive to imipenem. The rest of bacterial isolates had sensitivities to E. coli $88 \%$, Acinetobacter $80 \%$, Klebsiella species $67 \%$ and Peudomonas species $64 \%$. The meropenem is highly resistant in all the bacteria as compared to imipenem.

Conclusion: Increasing the trend of carbapenem resistance amongst Gram negative bacteria excluding Salmonella typhi was recorded.

Key words: Gram negative rods, Resistance, Spectrum
\end{abstract}

\section{INTRODUCTION}

The antibiograms have a significantly vital place for carbapenems. Carbapenems possess the broadest range of activity and greatest potency against Gram-positive and Gram-negative bacteria amongst the different $\beta$-lactams. As a consequence, these are frequently used as "last-line agents" or "antibiotics of last resort" when patients with infections become fatally ill or are suspected of harbouring resistant bacteria. ${ }^{1-3}$ Due to recent emergence of multidrugresistant (MDR) pathogens, this class of life saving drugs in under serious threat. ${ }^{4}$ As shown in several recent studies, resistance to carbapenems is increasing throughout the world. ${ }^{5-7}$ Concerning their role with regard to $\beta$-lactamase inhibition, our understanding of how to best use these agents is undergoing a renaissance despite this alarming trend.

The carbapenems exhibit an overall broader antimicrobial spectrumin vitroas compared to penicillins, cephalosporins, and $\beta$-lactam/ $\beta$-lactamase inhibitor combinations. ${ }^{8}$ Generally against Gram-positive bacteria, imipenem, panipenem, and doripenem are more effective antibiotics 8,9 whereas meropenem, biapenem, ertapenem, and doripenemare somewhat more effectual against Gramnegative organisms. ${ }^{8,10}$ There are certain significant considerations in this regard: (i) Ertapenemhas a more limited spectrum, ${ }^{11}$ and is not as active as imipenem or meropenem against $P$. aeruginosa; (ii) Against Acinetobacterbaumannii, meropenem is not as potent as imipenem or doripenem ${ }^{11}$; (iii) Considering $P$. Aeruginosa and $A$. baumannii, doripenem has lower MICs than do imipenem and meropenem. ${ }^{12}$

\section{MATERIALS AND METHODS}

It was a prospective, non-randomized, descriptive study conducted at Microbiology Department of Mughal Laboratories, Lahore over a period of 6 months from $1^{\text {st July }}$ 2019 to $31^{\text {st }}$ December 2019. All the culture samples received during this period were analysed. According to the current standardsorganisms were recognized by the microbiological techniques and Kirby Bauer Disc diffusion procedure was used for susceptibility testing according to the guidelines of Clinical and Laboratory Standards Institute (CLSI) 2020. The identified isolates were subjected to antimicrobial susceptibility testing using Agar disc diffusion methods. Zone of inhibitions were measured and reported according to Clinical Laboratory Standard Institutes Criteria (CLSI 2020) and susceptibilities of isolated bacteria against imipenem and meropenem were compared. Data analysis of the present research was carried out and their graphical representation and statistical analysis was determined by using Microsoft Excel and SPSS version 23.

\section{RESULTS}

The division of bacteria isolated were: E.coli $41 \%$, Psedomonas species 25\%, Klebsiella species 12\%, Salmonella typhi 11\%, Acinetobacter species 5\%, Proteus species $4 \%$, Citrobacter species $2 \%$. It was established that the most common bacteria isolated was E.coli followed by Pseudomonas and so on (Fig. 1).

The individual susceptibilities of isolated bacteria against imipenem (Table 1). Salmonella typhi, Citrobacter species and Proteus species were $100 \%$ sensitive to imipenem. The rest of bacterial isolates had sensitivities as 
under; E. coli $88 \%$, Acinetobacter $80 \%$, Klebsiella species $67 \%$ and Peudomonas species 64\% (Table 1).

The individual susceptibilities of isolated bacteria against meropenem are shown in table 2. Salmonella typhi was $100 \%$ sensitive and acinetobacter was completely resistant to meropenem. The rest of bacterial isolates had sensitivities as under; Citrobacter $50 \%$, E. coli $49 \%$, Pseudomonas species 29\%, Proteus species 25\% and Klebsiella species 17\% (Table 2).

The comparison of susceptibilities to imipenem and meropenem in all the bacterial isolates enrolled in the study. The graph clearly shows that meropenem is highly resistant in all the bacteria enrolled in the study as compared to imipenem (Fig. 2). Percentage resistance to meropenemagainst different isolates were; Acinetobacter $100 \%$, Proteus species $75 \%$, Pseudomonas species $68 \%$, Klebsiella species 67\%, E. coli 51\% and Citrobacter 50\%. There was no resistance observed in Salmonella typhi against both drugs and $p$ value was highly significant (0.0001).

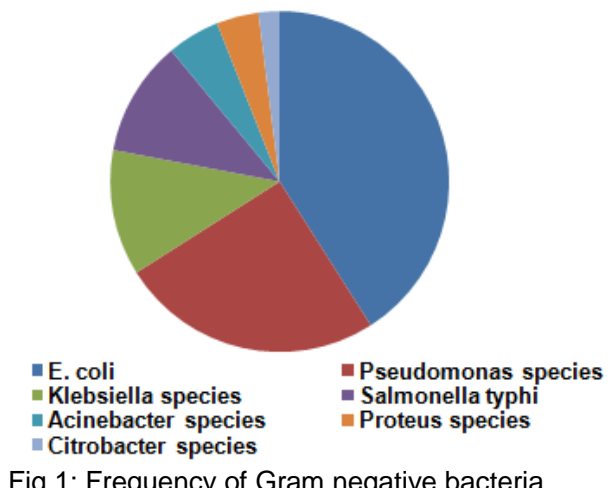

Table 1: Susceptibility profile of Gram negative bacteria against Imipenem on disc diffusion $(n=100)$

\begin{tabular}{|l|l|l|l|}
\hline \multirow{2}{*}{ Bacterial Isolate } & \multicolumn{3}{|l|}{ Imipenem } \\
\cline { 2 - 4 } & $\begin{array}{l}\text { Resistant } \\
\mathrm{N}(\%)\end{array}$ & $\begin{array}{l}\text { Intermediate } \\
\mathrm{N}(\%)\end{array}$ & $\begin{array}{l}\text { Sensitive } \\
\mathrm{N}(\%)\end{array}$ \\
\hline E. coli (41) & $4(10 \%)$ & $1(2 \%)$ & $36(88 \%)$ \\
\hline $\begin{array}{l}\text { Pseudomonas species } \\
(25)\end{array}$ & $7(28 \%)$ & $2(8 \%)$ & $16(64 \%)$ \\
\hline Citrobacter species (2) & - & - & $2(100 \%)$ \\
\hline Acinetobacter species (5) & $1(20 \%)$ & - & $4(80 \%)$ \\
\hline Klebsiella species (12) & $1(8 \%)$ & $3(25 \%)$ & $8(67 \%)$ \\
\hline Proteus species (4) & - & - & $4(100 \%)$ \\
\hline Salmonella typhi (11) & - & - & $\begin{array}{l}11 \\
(100 \%)\end{array}$ \\
\hline
\end{tabular}

Table 2: Susceptibility profile of Gram negative bacteria against Meropenem on disc diffusion $(n=100)$

\begin{tabular}{|l|l|l|l|}
\hline \multirow{2}{*}{ Bacterial Isolate } & \multicolumn{3}{|l|}{ Meropenem } \\
\cline { 2 - 4 } & $\begin{array}{l}\text { Resistant } \\
\mathrm{N}(\%)\end{array}$ & $\begin{array}{l}\text { Intermediate } \\
\mathrm{N}(\%)\end{array}$ & $\begin{array}{l}\text { Sensitive } \\
\mathrm{N}(\%)\end{array}$ \\
\hline E. coli (41) & $21(51 \%)$ & - & $20(49 \%)$ \\
\hline $\begin{array}{l}\text { Pseudomonas species } \\
(25)\end{array}$ & $17(67 \%)$ & $1(4 \%)$ & $7(29 \%)$ \\
\hline Citrobacter species (2) & $1(50 \%)$ & - & $1(50 \%)$ \\
\hline Acinetobacter species (5) & $5(100 \%)$ & - & - \\
\hline Klebsiella species (12) & $8(67 \%)$ & $2(16 \%)$ & $2(17 \%)$ \\
\hline Proteus species (4) & $3(75 \%)$ & - & $1(25 \%)$ \\
\hline Salmonella typhi (11) & - & - & 11 \\
& & & $(100 \%)$ \\
\hline
\end{tabular}

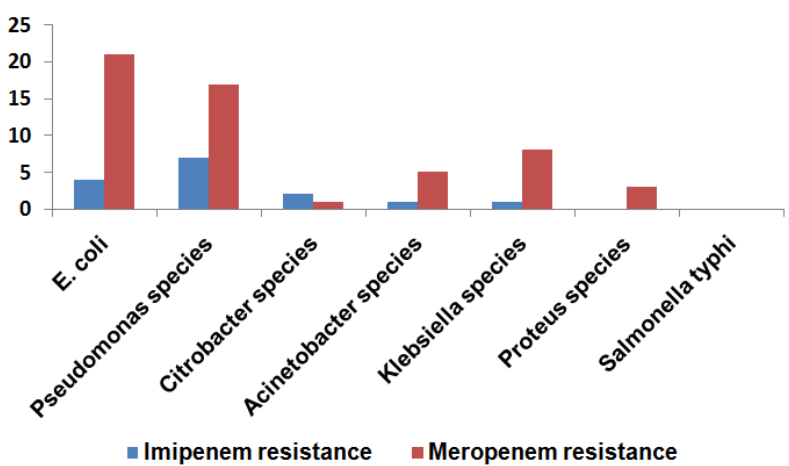

Graph 2: Resistance in Gram negative bacteria against Imipenem and Meropenemby disc diffusion $(n=100)$

\section{DISCUSSION}

Increasing drug resistance has been a peril and threat to society and a persistently growing global problem. Carbapenem (meropenem, imipenem) have been the most active broad-spectrum antimicrobial class amongst the beta lactam drugs, but because of rapidly growing drug resistance, this class of antibiotics is also under serious threat. In the current study, we analyzed and compared the susceptibilities of Gram negative bacteria against imipenem and meropenem. Each of them needs to be catered by special programs for reduction of resistance to antibiotics especially those which are most commonly used for treatment, as the pattern of resistance can be different in various populations.

During the study period, the most commonly isolated bacteria from different culture samples were $E$. coli followed by pseudomonas. Considering Imipenem individually, Salmonella typhi were $100 \%$ sensitive to imipenem. As carbapenems are the main stay of treatment due to rising resistance, the findings in our study were comparable to the XDR strains of Salmonella typhi earlier reported from Pakistan which were also found susceptible to carbapenems. In a study from Pakistanalmost $90 \%$ of patients with Salmonella typhi were sensitive to imipenem and meropenem. ${ }^{13}$

In the present study, E. coli was $88 \%$, Acinetobacter $80 \%$, Klebsiella species $67 \%$ and Peudomonas species $64 \%$ sensitive to imipenem, which was comparable to various studies conducted globally. ${ }^{14}$

The percentage of E. coli susceptiblity was $100 \%$ and the rate of Kelebsiella pneumonia susceptibility was $100 \%$ in another report. ${ }^{15}$ Higher susceptibility of Pseudomonas to imipenem in the range of $91.7 \%$ to $86 \%$ was observed from review of reports in other countries. ${ }^{16}$ Resistance of anaerobic gram-negative bacilli to imipenem was extremely low and was measured as $1 \%$ in a study from nine educational hospitals in France. ${ }^{17}$ The resistance of $E$. coli isolates to imipenem was $99.7 \%{ }^{18}$, in Saudi Arabia, whereas the resistance of this bacterium to imipenem in our study was $64 \%$. Susceptibility of some bacteria such as E. coli, Salmonella and Proteusto imipenem is satisfactory; however, the susceptibility of Pseudomonas to this antibiotic was dramatically lower in our region in comparison with other regions, when comparison of the results of our study and other similar studies in different regions in Iran and even other countries was done.Previous 
studies have demonstrated that anti-pseudomonal cephalosporins fail for the treatment of infections caused by Pseudomonas aeruginosa isolates, whereas imipenem proved to be a broad-spectrum carbapenem antibiotic with better activity against Pseudomonas aeruginosa. ${ }^{19}$ Furthermore, it has been observed that because of excessive use of this class of antibiotic and no other beta lactam drugs, there is emergence of imipenem-resistant Pseudomonas in hospitalized patients. ${ }^{20} \mathrm{~A}$ three-fold rise in the consumption of imipenem worldwide was also reported by certain studies.In this study, susceptibilities against meropenem, it was observed to be less sensitive as compared to imipenem other than Salmonella typhi which was $100 \%$ sensitive. ${ }^{13}$

The rest of bacterial isolates had sensitivities as under; Citrobacter 50\%, E.coli 49\%, Pseudomonas species $29 \%$, Proteus species $25 \%$ and Klebsiella species $17 \%$.Acinetobacter was completely resistant to meropenem. This is comparable to a study conducted in a tertiary care hospital in Iran. ${ }^{21}$

Although generally, meropenem is 2 to 16 fold more active than imipenem against Gram-negative aerobes ${ }^{22,23}$ and 4 to 16 fold more active against Enterobacteriaceae, but when we compared the study drugs, it was observed that percentage resistance to meropenem against the study isolates was more as compared to imipenem

\section{CONCLUSION}

Increasing the trend of carbapenem resistance amongst Gram negative bacteria, excluding Salmonella typhi was highlighted. Furthermore the curve was more inclined toward resistance to meropenem as compared to imipenem that is a different trend and new aspect. In order to improve the quality of empiric antimicrobial prescribing or guiding development of antimicrobial policies for such precious class of antibiotics, antimicrobial susceptibility surveillance programs represent one of the main recommendations to control resistant organisms.

\section{REFERENCES}

1. Bradley JS, Garau J, Lode H, Rolston KV, Wilson SE, Quinn JP. Carbapenems in clinical practice: a guide to their use in serious infection. Int J Antimicrob Agents 1999; 11(2):93-100

2. Paterson DL. Recommendation for treatment of severe infections caused by Enterobacteriaceae producing extended-spectrum $\beta$-lactamases (ESBLs). Clin Microbiol Infect 2000; 6:460-63.

3. Paterson DL, Bonomo RA. Extended-spectrum $\beta$ lactamases: a clinical update. Clin Microbiol Rev 2005; 18:657-86.

4. Queenan AM, Bush K. Carbapenemases: the versatile $\beta$ lactamases. Clin Microbiol Rev 2007; 20: 440-58.

5. Livermore DM, Warner M, Mustaq S, Doumith M, Zhang J, Woodford N. What remains against carbapenem-resistant Enterobacteriaceae? Evaluation of chloramphenicol, ciprofloxacin, colistin, fosfomycin, minocycline, nitrofurantoin, temocillin and tigecycline. Int $\mathrm{J}$ Antimicrob Agents 2011; 37(5):415-9.

6. Nordmann P, Picazo JJ, Mutters R, Korten V, Quintana A, Laeuffer JM, et al. Comparative activity of carbapenem testing: the COMPACT study. J Antimicrob Chemother 2011; 66(5): 1070-78.

7. Rossi F. The challenges of antimicrobial resistance in Brazil. Clin Infect Dis 2011; 52: 1138-43.

8. Bassetti M, Nicolini L, Esposito S, Righi E, Viscoli C. Current status of newer carbapenems. Curr Med Chem 2009; 16: 564-75.

9. Queenan AM, Shang W, Flamm R, Bush K. Hydrolysis and inhibition profiles of $\beta$-lactamases from molecular classes $A$ to $D$ with doripenem, imipenem, and meropenem. Antimicrob Agents Chemother 2010; 54: 565-9.

10. Perry CM, Ibbotson T. Biapenem. Drugs 2002; 62: 2221-35.

11. Oliver A, Levin BR, Juan C, Baquero F, Blazquez J. Hypermutation and the preexistence of antibiotic-resistant Pseudomonas aeruginosa mutants: implications for susceptibility testing and treatment of chronic infections. Antimicrob Agents Chemother 2004; 48:4226-33.

12. Mandell L. Doripenem: a new carbapenem in the treatment of nosocomial infection. Clin Infect Dis 2009; 49(Suppl. 1): S1-3.

13. Klemm EJ, Shakoor S, Page AJ, Qamar FN, Judge K, Saeed DK. Emergence of an extensively drug resistant Salmonella enteric serovar Typhi clone harboring a promiscuous plasmid encoding resistance to fluoroquinolones and third-generation cephalosporins. mBio 2018;9:1-18.

14. Khorshidi A, Sharif AR. Imipenem resistance among Gramnegative and Gram-positive bacteria in hospitalized patients. Iran J Public Health 2010; 39(2): 110-13.

15. Shahcheraghi F, Noveri H, Nasiri S. Detection of bla TEM \&bla SHV genes among clinical isolates of Escherichia coli from Tehran hospitals. Iranian J Med Microbial 2007;1(3):18.

16. Bouza E, Garcia-Garrote F, Cercenado E, Marín M, Díaz MS, Sánchez Romero I. Pseudomonas aeruginosa: a multicenter study in 136 hospitals in Spain. Rev Esp Quimioter 2003;16(1):41-52.

17. Behra-Miellet J, Calvet L, Mory F, Muller C, Chomarat M, Bézian MC, et al. Antibiotic resistance among anaerobic Gram-negative bacilli: lessons from a French multicentric survey. Anaerobe 2003;9(3):105-11.

18. Al-Tawfiq JA. Increasing antibiotic resistance among isolates of Escherichia coli recovered from inpatients and outpatients in a Saudi Arabian hospital. Infect Control Hosp Epidemiol 2006;27(7):748-53.

19. Cooper GL, Louie A, Baltch AL, Chu RC, Smith RP, Ritz WJ, et al. Influence of zinc on Pseudomonas aeruginosa susceptibilities to imipenem. J ClinMicrobiol1993;31(9):236670.

20. Troillet $\mathrm{N}$, Samore $\mathrm{MH}$, Carmali $\mathrm{Y}$. Imipenem resistant $\mathrm{P}$. aeruginosa: risk factors and antibiotic susceptibility patterns. Clin Infect Dis 1997;25(5):1094-8.

21. Rahbar M, Kabeh-Monnavar M, Vatan KK, Fadaei-haqi A, Shakerian F. Carbapenem resistance in Gram-negative bacilli isolates in an Iranian 1000-bed tertiary hospital. Pak J Med Sci 2008; 24(4): 537-40.

22. Kitzis MD, Acar JF, Gutmann L. Antibacterial activity of meropenem against Gram-negative bacteria with a permeability defect against staphylococci. J Antimicrob Chemother 1989; 24(Suppl A):125-32.

23. Lewis C, Doherty C, Gowan J. In vitro activities of meropenem PD 127391, PD 131628, ceftazidime chloramphenicol cotrimoxazole and ciprofloxacin against Pseudomonas cepacia. Antimicrob Agents Chemother 1993; 37: 23-5. 